\title{
A new approach for an efficient human resource appraisal and selection
}

\author{
Hachicha Raoudha, Dafaoui El Mouloudi, Hadji Selma, El Mhamedi Abderrahman \\ University of Paris (France) \\ r.mkaouar@iut.univ-paris8.fr, dafaoui@iut.univ-paris8.fr, \\ selma.hadji@gmail.com, a.elmbamedi@iut.univ-paris8.fr
}

Received: December 2011

Accepted: October 2012

\section{Abstract:}

Purpose: The aim of the paper is to provide a decision making tool for solving a multicriteria selection problem that can accommodate the qualitative details in relations with the task requirements and candidates' competences.

Design/methodology/approach: Our inquiry emphasizes the use of the 2-tuple linguistic representation model to aggregate linguistic assessments of acquired and required competence resources generated by a group of appraisers. The aggregated levels are the inputs of an extended version of the TOPSIS method which provides a candidates' ranking.

Findings: The quality and efficiency of the proposed approach were confirmed through a real life application from a university context. It ensures a better management of the available candidates. Moreover, it allows facing the circumstances of absenteeism, identifying the need of training, and so on.

Originality/value: The 2-tuple linguistic model is adequate to propose objective aggregated linguistic assessments without loss and distortion of the initial competence evaluations provided by each appraiser. Besides, the use of TOPSIS avoids the complex calculation and can be exploited easily in practice.

Keywords: Competence, decision making, multi-criteria, 2-tuple, TOPSIS. 


\section{Introduction}

To respond to the fierce competition, companies have to focus on the creation of sustained competitive advantages. As performance depend more on the management of innovation and diversification, intangible resources are more likely than tangible ones to produce a competitive advantage. In such a context, human resources, with their cognitive and decision making capacities, appeared as the 'new' key component of the performance (Bennour \& Crestani, 2007).

Today, the emergence of several characteristics of the organization's personnel, involving personnel knowledge, experience, collaborative information stemming from social network, helps to introduce the competence concept and to stress on his importance into the realization of organization goals. This concern opens horizons for researchers to develop more adaptive and effective competence management techniques among which some have important implication on Human Resources selection and performance appraisal.

Competence-based appraisal and selection problem have been recognized as a central problem. The accuracy of the resulting selection is built on both appraiser opinion and a painstaking task analysis to facilitate the definition of the appropriate selection criteria and their relative importance degree. Therefore, these criteria help the appraiser to provide his opinions about the competence level of a candidate when performing the corresponding task. Nevertheless, since the appraiser's judgment is inherently subjective, his opinion may lead to an unfaithful selection result. That is why it seems plausible to involve different decisionmakers' opinions. As the problem variables are vague and imprecise, the selection problem should be based on a linguistic evaluation method to represent the decision-makers' opinions by means of linguistic variables whose values are not numbers but words or sentences in a natural or artificial language. This may help avoiding the uncertain interpretation.

In the framework of the paper, we intend to provide a decision making tool to a manager for solving a multi-criteria selection problem that can accommodate the qualitative details in relation to the task requirements and candidates' competences. Our challenge is to ensure an improvement in human resources appraisal and selection through a more flexibility and better treatment of information with uncertainty and vagueness. Accordingly, we opt, at first, for the use of the most objective and effective evaluation method, the 2-tuple linguistic representation model, to deal with linguistic assessment information. This model proves itself by its simplicity and its robustness by overcoming the loss and the distortion of qualitative information and by providing final results always expressed in the initial linguistic domain (Herrera \& Martinez, 2001). Then, we suggest carrying out one of the multi-criteria techniques, namely, TOPSIS (Technique for Order Preference by Similarity to Ideal Solution). On one hand, TOPSIS allows ranking and therefore finding a compromise solution for the selection of the best candidate to 
each of the predefined tasks according to the different required criteria. On the other hand, it also informs on the degree of similarity between the required and acquired levels. Such information is not provided by the remaining multi-criteria decision making methods. It assists the manager to make the right decision about different internal policies such as identifying individual substitution alternatives in cases of absenteeism, identifying the need of training, improving the candidate's matching to tasks based on a detailed comparison with regard to the reference competence resources levels, etc.

In the next section, a review of literature is described, including the competence evaluation and selection problem. A brief introduction of the basic definitions of the 2-tuple linguistic representation model and the TOPSIS method are presented. Then, we outline the different steps of the proposed approach based on the combination of the linguistic competence evaluation process and the TOPSIS multi-criteria decision making method. A real example from a university context is developed to illustrate each step of the proposed approach. Finally, some conclusions are pointed out in the end.

\section{Related work}

Managing competences is a complex and a subtle process. While there are three points of view considered in the research on competences (Boucher, Bonjour \& Grabot, 2007), our focus in this paper is on the structural and functional view that can be managed at the tactical level of decision. It concerns mainly the identification of the specific competence requirements of the tasks and the evaluation of both the acquired and required competences. This kind of information is therefore used for the eventual resolution of a selection problem.

\subsection{Personnel selection problem based on competence evaluation}

The human resources evaluation processes are in constant evolution since the resulting assessments are required in assisting ranking and decision-making problem. One of the evaluation procedures quite often used is performance appraisal (Banks \& Roberson, 1985; Baron \& Kreps, 1999). Performance appraisal refers to the process through which an observer, often a supervisor, rates the task performance of a candidate (Denisi, Cafferty \& Meglino, 1984) according to predefined criteria such as competences. Several performance appraisal goals are highlighted, namely: evaluation goals, management goals, coaching and development goals (Beer, 1981; Chang, Cheng \& Chen, 2007). In the following, recent studies that underline the evaluation goals are presented. Basically, we emphasize the competencebased evaluation and selection processes.

The research by Wi, Oh, Mun and Jung (2009) suggest keywords based evaluation method. It seeks to provide evaluation for the knowledge competence of each candidate likely to be selected as a member of a R\&D project. The considered knowledge competence consists of 
personnel knowledge (Know-What, Know-How) and knowledge from social network (KnowWho). Its score is evaluated using personal knowledge score, based on a comparison between the keywords required in the project and those in a candidate's publications, and familiarity score, evaluated according to the number of co-authors and average intervals of publications. Based on these objective evaluations, a multi-objective mathematical programming is proposed to select a minimum number of R\&D project team members with high knowledge competence and familiarity and resolved by a genetic algorithm. The approach is appealing. However, it is quite difficult to put into practice in another context. Belkadi, Bonjour and Dulmet (2007) opt to formalize the competence concept, defined as cognitive capacities and action rules, considering the mathematically estimated values of the different situations' characteristics of an actor's activity. Using the fuzzy inference system, this competence characterization enables the assessment of the level of mastery in an acquired competence. Although well defined and detailed, the resulting competence characterization is not suited to every kind of situations and needs expertise in the field to list the different situations and their respective characteristics.

Golec and Kahya (2007) attempt to evaluate each employee competence regarding predefined organization goals. At this end, the authors identify competency-based factors and their corresponding indicators. So, a linguistic assessment of each employee competency for each indicator of each factor is discussed between human expert and operation manager. The fuzzy set theory is used to express the performance of each employee and therefore to select the best employee.

Researches by Chang et al. (2007) and Moon, Lee and Lim (2010) present an efficient performance appraisal system based on linguistic evaluations. Appraisers provide linguistic opinions about a certain number of predefined performance criteria. The assessments are therefore converted into fuzzy numbers to be aggregated. The aggregated evaluation expressed with fuzzy numbers cannot escape the problem of interpretation vagueness and therefore from the difficulty of ranking. For that reason, (Chang et al., 2007) propose a metric distance to rank the ensuing fuzzy numbers. The results are compared with the intuition ranking method and the Lee and Li's fuzzy mean/spread method (Lee \& Li, 1988) and proved as the best. (Moon et al., 2010) propose a new ranking procedure based on the calculation of both the metric distance and fuzzy mean value. While the metric distance allows the comparison between the candidates' levels and the ideal recorded one, the fuzzy mean value shows the difference from the ideal solution's fuzzy mean. These ranking measures allow the determination of the ideal solution as a collection of the best solutions in each criterion.

So far, in literature, different multi-criteria group decision-makers approaches are proposed for dealing with linguistic assessment information. A new group decision making method based on "computing with words" is introduced by De Andrés, Garcia-Lapresta and Martinez (2010). 
They propose a $360^{\circ}$ performance appraisal model. It is based on the judgment from everyone with whom the worker comes in contact in order to manage the uncertainty and subjectivity of such assessments. The assessments are modelled by means of the linguistic 2-tuple computational model introduced by Herrera and Martinez (2000). The proposed model manages multi-granular linguistic labels provided by appraisers in order to compute collective assessments about the employees' skills that will be used by the management team to make the final decision about the promotion of one of them.

In the light of the above literature review, authors have not agreed about a unique definition of competence concept. Although there is an interaction between the proposed ones, the understanding of the concept is influenced by the different contexts (Mkaouar Hachicha, Dafaoui \& El Mhamedi, 2009). Besides, as it is difficult to give exact numerical values to express opinions based on human perception to measure competence concept, almost all the authors use the fuzzy logic, initiated by Zadeh (1975), as the most suitable theory to express the inherent imprecision. Unfortunately, it needs a choice of inference rules that is neither exhaustive nor final and provides an estimated quantitative value that cannot be considered as accurate and reliable.

In such circumstances, we noticed that the 2-tuple representation model (Herrera \& Martinez, 2000 ) is the most suitable tool to ensure a better reconciliation between linguistic and numerical information.

Based on the aforementioned remarks, we propose a new approach that aims at selecting the best candidate whose competence components levels match well with the task requirements. For that purpose and contrary to the proposal of the literature studies, our inquiry emphasizes the use of the 2-tuple linguistic representation model to determine the appraisers' opinions about both acquired and required competence components levels. Given the resulting 2-tuple assessments, we suggest an extended version of the TOPSIS method to get the candidates' ranking based on a similarity degree between required and acquired competence components levels (Mkaouar Hachicha et al., 2010). So, it is obvious to select the best candidate.

For a better understanding of the proposed approach, it is worthy to introduce the basic definitions of these methods in the next sub-section.

\subsection{Preliminaries}

\section{The 2-tuple linguistic representation model}

The 2-tuple linguistic representation model, initially proposed by Herrera \& Martinez (2000), is basically based on "computing with words" process. It proves itself by its extensive application areas, its simplicity and its robustness in overcoming the loss and the distortion of qualitative information that have promoted its reputation in many fields. It was applied to problems 
involving multiple criteria: selection of an ERP system (Liao, Li \& Lu, 2007), project selection (Halouani, Chabchoub \& Martel, 2009), evaluation of the suitability of implementing an ERP system (Sanchez, Martinez, Garcia-Martinez, Herrera \& Herrera-Viedma, 2009), evaluation of the intellectual capital performance (Tai \& Chen, 2009), evaluation of the Knowledge Management Capability (Fan, Feng, Sun \& Ou, 2009).

The key idea behind the 2-tuple fuzzy linguistic model is the representation of any linguistic assessment information with a pair of values named 2-tuple $\left(s_{i}, \alpha\right)$.

- Let $S=\left\{s_{0}, s_{1}, \ldots, s_{g}\right\}$ be a linguistic term set and $\beta \in[0, g]$ a value representing the result of a symbolic aggregation operation, then the 2-tuple that expresses the equivalent information to $\beta$ is obtained as follows:

$$
\begin{aligned}
& \Delta:[0, g] \rightarrow S \times[-0.5,0.5) \\
& \Delta(\beta)=\left(s_{i}, \alpha\right) \begin{cases}s_{i}, & i=\operatorname{round}(\beta), \\
\alpha=\beta-i, & \alpha \in[-0.5,0.5),\end{cases}
\end{aligned}
$$

Where round (.) is the usual round operation and $\alpha$ is a symbolic translation that supports the "difference of information" between an amount of information $\beta \in[0, g]$ and the closest value in $\{0, \ldots, g\}$ that indicates the index of the closest linguistic term in S.

- There is always a $\Delta^{-1}$ function, such that, from a 2 -tuple it returns its equivalent numerical value $\beta \in[0, g]$ in the interval of granularity of $S$.

$$
\begin{aligned}
& \Delta^{-1}: S \times[-0.5,0.5) \rightarrow[0, g], \\
& \Delta^{-1}\left(s_{i}, \alpha\right)=i+\alpha=\beta
\end{aligned}
$$

Remark: The conversion of a linguistic term $s_{i}$ into a linguistic 2-tuple is based on adding a value 0 as a symbolic translation, i.e., $s_{i} \in S \Rightarrow\left(s_{i}, 0\right)$.

Based on the above definitions, we can easily present the models of comparison and of aggregation between two or more 2-tuple assessments (Herrera \& Martinez, 2000):

- The comparison of 2-tuple:

Let $\left(s_{i}, \alpha_{i}\right)$ and $\left(s_{j}, \alpha_{j}\right)$ be two 2 -tuple defined in the same linguistic term set:

(i) When $i<j$, then $\left(s_{i}, \alpha_{i}\right)$ is worse than $\left(s_{j}, \alpha_{j}\right)$

(ii) When $i=j$

(a) If $\alpha_{i}=\alpha_{j}$ then $\left(s_{i}, \alpha_{i}\right)$ is equal to $\left(s_{j}, \alpha_{j}\right)$

(b) If $\alpha_{i}<\alpha_{j}$ then $\left(s_{i}, \alpha_{i}\right)$ is worse than $\left(s_{j}, \alpha_{j}\right)$ 
(c) If $\alpha_{i}>\alpha_{j}$ then $\left(s_{i}, \alpha_{i}\right)$ is better than $\left(s_{j}, \alpha_{j}\right)$

- The aggregation of 2-tuple:

(i) Let $a=\left\{\left(b_{1}, \alpha_{1}\right),\left(b_{2}, \alpha_{2}\right), \ldots,\left(b_{n}, \alpha_{n}\right)\right\}$ be a set of linguistic 2-tuples, the 2-tuple arithmetic mean operator $\varphi_{1}$ is

$$
\varphi_{1}\left[\left(b_{1}, \alpha_{1}\right),\left(b_{2}, \alpha_{2}\right), \ldots,\left(b_{n}, \alpha_{n}\right)\right]=\Delta\left(\sum_{i=1}^{n} \frac{\Delta^{-1}\left(b_{i}, \alpha_{i}\right)}{n}\right)
$$

(ii) Let $a=\left\{\left(b_{1}, \alpha_{1}\right),\left(b_{2}, \alpha_{2}\right), \ldots,\left(b_{n}, \alpha_{n}\right)\right\}$ be a set of linguistic 2 -tuples and $\left\{w_{1}, w_{2}, \ldots, w_{n}\right\}$ be their associated weights. The 2-tuple weighted average operator $\varphi_{2}$ is

$$
\varphi_{2}\left[\left(b_{1}, \alpha_{1}\right),\left(b_{2}, \alpha_{2}\right), \ldots,\left(b_{n}, \alpha_{n}\right)\right]=\Delta\left(\frac{\sum_{i=1}^{n} \Delta^{-1}\left(b_{i}, \alpha_{i}\right) w_{i}}{\sum_{i=1}^{n} w_{i}}\right)
$$

\section{$\underline{\text { TOPSIS }}$}

TOPSIS is a Multi-Criteria Decision Making method developed by (Hwang \& Yoon, 1981). It is based on choosing the best alternative, which has the shortest distance from the positive-ideal alternative and the longest distance from the negative-ideal alternative. In its initial version, it is well employed in organization performance evaluation (Sadi-Nezhad \& Damghani, 2010; Wu, Tzeng \& Chen, 2009). Some authors propose extended version of TOPSIS to deal with decision-making problems with interval data (Jahanshahloo, Hosseinzadeh Lotfi \& Izadikhah, 2006), to develop a methodology for solving multi-person multi-criteria decision-making problems in fuzzy environment (Chen, 2000; Chen, Lin \& Huang, 2006; Torfi, Farahani \& Rezapour, 2010),...

The procedure of the TOPSIS can be expressed in a series of steps:

- Calculate the normalized decision matrix. The normalized value $n_{i j}$ is calculated as:

$$
n_{i j}=x_{i j} / \sqrt{\sum_{j=1}^{m} x_{i j}^{2}}, \quad j=1, \ldots, m \text { and } i=1, \ldots, n
$$

Where $x_{i j}$ is the rating of alternative $A_{j}$ with respect to criterion $C_{i}$.

- Calculate the weighted normalized decision matrix. The weighted normalized value $v_{i j}$ is calculated as

$$
v_{i j}=w_{i} n_{i j}, \quad j=1, \ldots, m \text { and } i=1, \ldots, n
$$

Where $w_{i}$ is the weight of the $i$ th criterion, and $\sum_{i=1}^{n} w_{i}=1$ 
- Determine the positive and negative ideal solution

$$
\begin{aligned}
& A^{+}=\left\{v_{1}^{+}, \ldots, v_{n}^{+}\right\}=\left\{\left(\operatorname{Max}_{j} v_{i j} \backslash i \in I\right),\left(\operatorname{Min}_{j} v_{i j} \backslash i \in J\right)\right\} \\
& A^{-}=\left\{v_{1}^{-}, \ldots, v_{n}^{-}\right\}=\left\{\left(\operatorname{Min}_{j} v_{i j} \backslash i \in I\right),\left(\operatorname{Max}_{j} v_{i j} \backslash i \in J\right)\right\},
\end{aligned}
$$

Where $I$ is associated with benefit criteria (the larger the evaluation, the greater the preference) and $J$ is associated with cost criteria (the smallest the evaluation, the greater the preference).

- Calculate the separation measures, using the n-dimensional Euclidean distance. The separation of each alternative from the ideal solution is given as

$$
d_{j}^{+}=\left\{\sum_{i=1}^{n}\left(v_{i j}-v_{i}^{+}\right)^{2}\right\}^{1 / 2}, \quad j=1, \ldots, m
$$

Similarly, the separation from the negative ideal solution is given as

$$
d_{j}^{-}=\left\{\sum_{i=1}^{n}\left(v_{i j}-v_{i}^{-}\right)^{2}\right\}^{1 / 2}, \quad j=1, \ldots, m
$$

- Calculate the relative closeness to the ideal solution. The relative closeness of the alternative $A_{j}$ with respect to $A^{+}$is defined as

$$
R_{j}=d_{j}^{-} /\left(d_{j}^{+}+d_{j}^{-}\right), \quad j=1, \ldots, m
$$

Since $d_{j}^{-} \geq 0$ and $d_{j}^{+} \geq 0$, then, clearly, $R_{j} \in[0,1]$.

- Rank the alternatives in a deacreasing order of $R_{j}$.

\section{Proposed approach}

To ensure a continuous organization success, managers have the challenge to place the right candidate in the right task. They have to be aware in identifying the available competence network based on the task requirements lists and in using such information to make the right decision in managing it. A systematic estimation of the personnel's working ability and performance is therefore indispensable. The 2-tuple representation model can be used as one of the most objective and effective evaluation methods. Based on these findings, a suitable decision-making method, e.g., TOPSIS, can be set up.

Considering the competence evaluation and selection problem, the general framework of our approach consists of different steps inspired from the decision analysis scheme proposed by (Martinez, 2007) and summarized in Figure 1. Therefore, a stepwise procedure description as well as a real world application are developed to show the relevance of the method. 


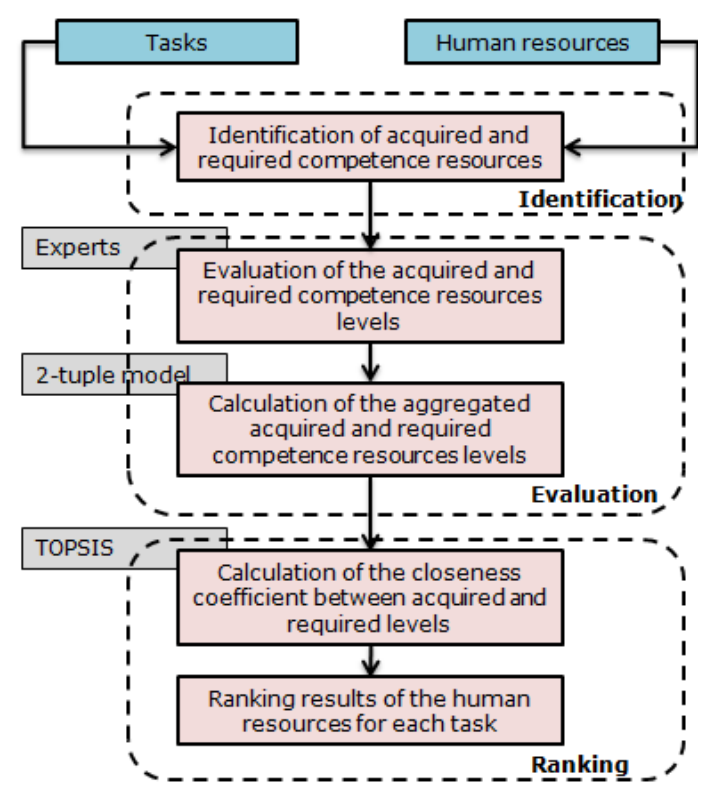

Figure 1. The proposed approach

\subsection{Evaluation problem of competence level}

\section{Step1: Competence identification}

In the last decade, scientific researches in industrial engineering field provide a fairly rich literature on the competence concept. Therefore, different competence definitions have been proposed. Our aim is to pick up the adequate one to the current problem. Indeed, it is trivial to notice that each competence, either acquired by the candidates or required by the tasks, consists implicitly or explicitly of three categories i.e., knowledge, know-how and know-whom.

First, let us define those categories and detail their sub-sets (=resources) (Harzallah \& Vernadat, 2002):

- Knowledge: it concerns everything learned at school or acquired in training. In this category we can find:

- Theoretical knowledge: it includes theorems, concepts, laws...

- Knowledge of the existent: it covers the specific knowledge about the domain or the environment in which the competence is carried out.

- Knowledge of the procedures: it is related to the need in dealing with procedures, methods...

- Know-how: it is the skill (operational knowledge). It concerns the practical application of procedures. It may include intuitions, tricks... It can be broken up into

- Procedural know-how: each actor has to know-how to apply a procedure, a method. 
- Empirical know-how: it covers the individual capacities for analyzing a current context, extracting the relevant information and then organizing his work (prioritize the various actions to do).

- Know-whom: it is an individual dependent. It is concerned with aspect related to performing tasks in a changing context. We can find:

- Relationship aspects: it is related to all individual relations when he works.

- Cognitive capacities: it is the capacity to react and make the right decision when faced with unexpected events. It is more appreciated through innovative reactions.

-Behaviors: such as curiosity, motivation...

Table 1 summarizes in detail the proposed competence resources categorization.

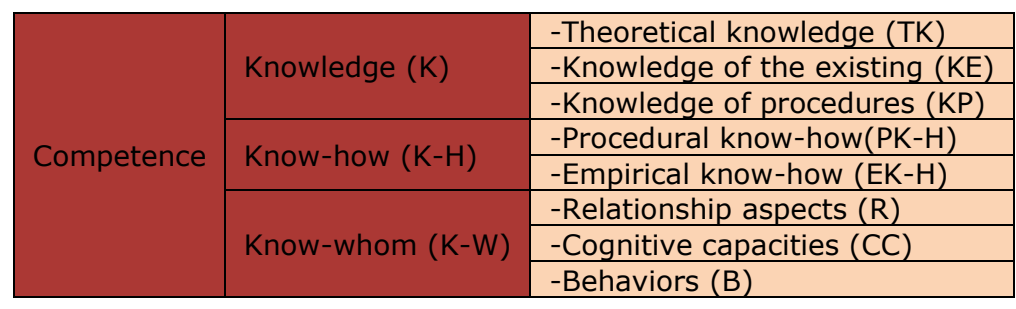

Table 1. Competence resources categorization (Harzallah \& Vernadat, 2002)

\section{Step 2: Competence resources linguistic evaluation}

A good competence evaluation needs rigorous assessment provided by a number of experts for the involved candidates with regard to the tasks. In order to act as a judge, the appraiser needs a scale with which to give his opinion. The choice of linguistic scale must be appropriate to the context. It implies the choice of the suitable linguistic term sets and their semantics.

The proposed linguistic term sets could be defined in an arbitrary universe of discourse. The semantics of the linguistic information may be assigned to the set of five, seven or nine terms. It informs about the capacity of distinction that can be expressed; the more knowledge, the more terms. According to the competence resources categorization shown in table 1 and to the proposed scale for the evaluation, each expert can express thoughtfully his opinion.

To avoid the subjective assessment, we propose to aggregate all the experts' opinions based on the 2-tuple linguistic representation model. The following notation is used in the remaining text:

Expert $I(I=1,2, \ldots, L)$

Candidate $i(i=1,2, \ldots, I)$

Module $j(j=1,2, \ldots, J)$

Competence resource $k(k=1,2, \ldots, K)$

$C a_{i k j l} \quad$ Evaluation of competence resource $k$ of candidate $i$ provided by expert $/$ according to each module $j$

$\alpha_{i k j l} \quad$ Symbolic translation of the evaluation $C a_{i k j l}$ 


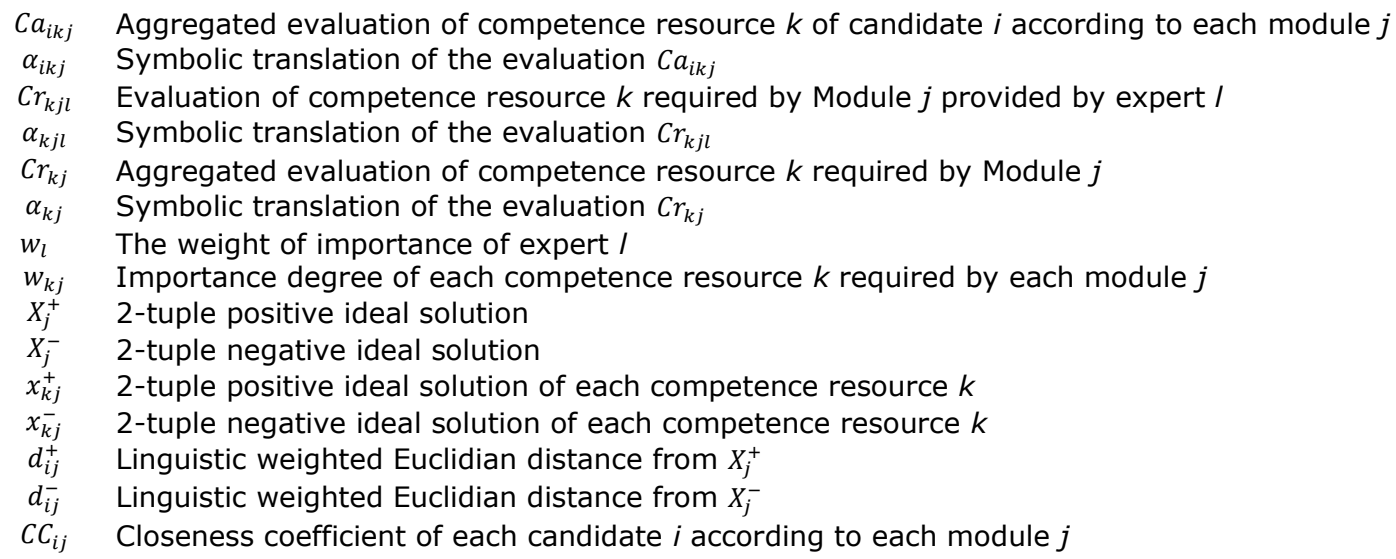

\section{Step 3: Aggregation of the experts' opinions}

In any evaluation problem, each expert provides his opinion with regard to different tasks. Since we try to propose a generic evaluation method, we assume that the experts' opinions do not have the same importance. By reference to equation (4), the aggregated acquired competence resource level, $C a_{i k j}$, is expressed as follows:

$$
\begin{aligned}
& \left(C a_{i k j}, \alpha_{i k j}\right)=\Delta\left(\sum_{l=1}^{L} \Delta^{-1}\left(C a_{i k j l}, \alpha_{i k j l}\right) w_{l} / \sum_{l=1}^{L} w_{l}\right) \\
& \forall j=1,2, \ldots, J ; \forall k=1,2, \ldots, K ; \forall i=1,2, \ldots, I
\end{aligned}
$$

The same work (from step 1 to step 3 ) has to be processed again for the determination of the aggregated required levels, $C r_{k j}$. Indeed, each expert is invited to express his opinion about the level of each competence resource required by each task. An aggregated required level for each competence resource can be calculated as follows :

$$
\left(C r_{k j}, \alpha_{k j}\right)=\Delta\left(\sum_{l=1}^{L} \Delta^{-1}\left(C r_{k j l}, \alpha_{k j l}\right) w_{l} / \sum_{l=1}^{L} w_{l}\right),
$$

The resulting aggregated acquired and required competence resources levels are therefore considered as inputs for the selection problem. The aim is to ensure effective and efficient task performance according to the fit of the acquired and the required competence resources levels.

\subsection{Selection problem}

\section{Step 4: Importance degree of required competence resources}

For each task, the required competence resources may not be of equal importance. As the required levels have been defined in the previous sub-section, it is possible to deduce the importance degree of each competence resource required by each task, $w_{k j}$ : 


$$
w_{k j}=\Delta^{-1}\left(C r_{k j}, \alpha_{k j}\right) / \sum_{k=1}^{K} \Delta^{-1}\left(C r_{k j}, \alpha_{k j}\right) \quad \forall j=1,2, \ldots, J
$$

Where $\sum_{k=1}^{K} w_{k j}=1$

$$
\forall j=1,2, \ldots, J
$$

\section{Step 5: The TOPSIS based calculation process}

In the light of the available information, it becomes possible to get a ranking of the candidates for each task and then select the best one. We propose a method based on the principle of TOPSIS method in which the alternatives are ranked by their distances between positive and negative ideal solution (Yoon and Hwang, 1995). In here, we note that the set of the considered competence resources are benefit criteria.

According to the 2-tuple aggregated competence resources evaluations given by equation 12 and 13 and according to equation 7 and 8, the 2-tuple positive ideal solution $X_{j}^{+}$and the 2tuple negative ideal solution $X_{j}^{-}$can be defined:

Where

$$
\begin{aligned}
& X_{j}^{+}=\left(x_{1 j}^{+}, x_{2 j}^{+}, \ldots, x_{K j}^{+}\right) \\
& X_{j}^{-}=\left(x_{1 j}^{-}, x_{2 j}^{-}, \ldots, x_{K j}^{-}\right)
\end{aligned}
$$

$$
\begin{aligned}
& x_{k j}^{+}=\left\{\begin{array}{cc}
\left(C r_{k j}, \alpha_{k j}\right) & \text { if }\left(C r_{k j}, \alpha_{k j}\right)>\left(C a_{i k j}, \alpha_{i k j}\right) \\
\operatorname{Max}_{i}\left(C a_{i k j}, \alpha_{i k j}\right) & \text { if }\left(\operatorname{Cr}_{k j}, \alpha_{k j}\right)<\left(\operatorname{Max}_{i}\left(\operatorname{Ca}_{i k j}, \alpha_{i k j}\right)\right)
\end{array}\right. \\
& x_{k j}^{-}=\operatorname{Min}_{i}\left(\operatorname{Ca}_{i k j}, \alpha_{i k j}\right) \\
& i=1,2, \ldots, I ; j=1,2, \ldots, J ; k=1,2, \ldots, K
\end{aligned}
$$

According to the principles of the TOPSIS technique (cf. section 2.3), the positive and negative ideal solutions are respectively the best and the worst acquired levels for each competence resource. Nevertheless, in the current research context, we notify that the 2-tuple positive ideal solution $x_{k j}^{+}$of each competence resource, given by equation 17 , is not always the best level among the recorded ones. Where all the acquired levels for one competence resource are lower than the required one, we prefer to assume the required level as the positive ideal solution. This is approved since we seek for the best matching between candidates' competences and the modules requirements.

When the positive and negative ideal solutions have been determined based on equations 15, 16,17 and 18 , it is worthy to adapt the equation 9 and 10 for the calculation of the linguistic weighted Euclidian distance of each candidate evaluation from $X_{j}^{+}$and $X_{j}^{-}$. The resulting expressions can be written as:

$$
\begin{gathered}
d_{i j}^{+}=\left(\sum_{k=1}^{K} \frac{w_{k j}\left[\Delta^{-1}\left(C a_{i k j}, \alpha_{i k j}\right)-\Delta^{-1}\left(x_{k j}^{+}\right)\right]^{2}}{\sum_{k=1}^{K} w_{k j}}\right)^{1 / 2} i=1,2, \ldots, I ; j=1,2, \ldots, J \\
d_{i j}^{-}=\left(\sum_{k=1}^{K} \frac{w_{k j}\left[\Delta^{-1}\left(C a_{i k j}, \alpha_{i k j}\right)-\Delta^{-1}\left(x_{k j}^{-}\right)\right]^{2}}{\sum_{k=1}^{K} w_{k j}}\right)^{1 / 2} i=1,2, \ldots, I ; j=1,2, \ldots, J
\end{gathered}
$$




\section{Step 6: Final selection result}

To rank the candidates from the best to the worst, a $\left(C C_{i j}\right)$ closeness coefficient of each candidate $i$ according to each module $j$ is defined, by reference to equation 11 , as follows:

$$
C C_{i j}=d_{i j}^{-} / d_{i j}^{+}+d_{i j}^{-} \quad i=1,2, \ldots, I ; j=1,2, \ldots, J
$$

The ranking is provided according to the descending order of $C C_{i j}$.

In the case of closeness coefficient equality between two or more candidates, tie-breaking is necessary according to the following rule: the best candidate is a priori the one who has the higher aggregated level in the most important resources of competence for the considered module.

\section{Real life application}

To illustrate and test the feasibility of the proposed approach, we develop an example depicted from real life problem. It is about the evaluation and the ranking of lecturers for a certain number of modules in the University Institute of Technology of Montreuil (IUT of Montreuil). The problem arises as long as the selection of the lecturer for one module is performed randomly according to the past affectations. That is, when one lecturer worked on one module the several past years, systematically it is attributed to him the next years. Such reflection is allowed even with the arrival of other candidates having the appropriate competence to perform it.

Our aim is to produce fair selection decisions that ensure the minimization of the gap between candidates' competences and the corresponding module requirement levels.

\subsection{Competence identification}

As the IUT of Montreuil consists of different departments, we have chosen to work on the QLIO department (Quality, Logistics of Industry, Organization), especially, on 4 modules of the third semester (M1, M2, M3 and M4). In this example, one task is one of the four predefined modules. The identification of the resources of competence required by each module is performed using the "National Pedagogical Curriculum" (Table 2). 


\begin{tabular}{|c|c|c|c|c|}
\hline & Module 1 (M1) & Module 2 (M2) & Module 3 (M3) & Module 4 (M4) \\
\hline TK & Informatics tools & $\begin{array}{c}\text { Production process, supply } \\
\text { management }\end{array}$ & $\begin{array}{c}\text { Statistics, } \\
\text { maintenance } \\
\text { management }\end{array}$ & $\begin{array}{l}\text { Linear programming, } \\
\text { graph theory }\end{array}$ \\
\hline KE & $\begin{array}{l}\text { Security standards of } \\
\text { the working space }\end{array}$ & $\begin{array}{l}\text { Be familiar to the equipment } \\
\text { in the university workshop }\end{array}$ & - & - \\
\hline $\mathbf{K P}$ & $\begin{array}{l}\text { Principles of database } \\
\text { management systems }\end{array}$ & Performance indicator & Default tree, AMDEC & Optimization problem \\
\hline PK-H & Use of Access, SQL & Use of the software GPAO & $\begin{array}{c}\text { Use of the software } \\
\text { GMAO }\end{array}$ & $\begin{array}{c}\text { Use of informatic } \\
\text { software for illustration }\end{array}$ \\
\hline EK-H & Manage the bugs & $\begin{array}{l}\text { Implementation of the } \\
\text { storage process in the } \\
\text { university workshop }\end{array}$ & $\begin{array}{c}\text { Create new work } \\
\text { situations for a better } \\
\text { learning }\end{array}$ & $\begin{array}{l}\text { Detect easily the errors } \\
\text { of matrix calculation }\end{array}$ \\
\hline $\mathbf{R}$ & $\begin{array}{l}\text { Manage the } \\
\text { communication with } \\
\text { students }\end{array}$ & $\begin{array}{l}\text { Manage the communication } \\
\text { with students }\end{array}$ & $\begin{array}{l}\text { Manage the } \\
\text { communication with } \\
\text { students }\end{array}$ & $\begin{array}{l}\text { Manage the } \\
\text { communication with } \\
\text { students }\end{array}$ \\
\hline $\mathbf{C C}$ & $\begin{array}{l}\text { Manage conflict } \\
\text { situations }\end{array}$ & Manage conflict situations & $\begin{array}{c}\text { Manage conflict } \\
\text { situations }\end{array}$ & $\begin{array}{l}\text { Manage conflict } \\
\text { situations }\end{array}$ \\
\hline B & $\begin{array}{l}\text { Curiosity about the } \\
\text { students' attitudes }\end{array}$ & $\begin{array}{c}\text { Curiosity about the students' } \\
\text { attitudes }\end{array}$ & $\begin{array}{l}\text { Curiosity about the } \\
\text { students' attitudes }\end{array}$ & $\begin{array}{l}\text { Curiosity about the } \\
\text { students' attitudes }\end{array}$ \\
\hline
\end{tabular}

Table 2. The considered competence resources of each module

\subsection{Competence resources linguistic evaluation}

The potential lecturers are those that actually teach one of the aforementioned modules and those who are likely to work on certain modules. Ultimately, we name five candidates (C1, C2, C3, C4 and C5). In order to avoid any conflict problem, we choose to hide the name of the candidates. The evaluation of the acquired and the required competence resources levels is done by three experts, namely, the actual department head and its two predecessors. For that purpose, we have established a questionnaire and presented it to each expert.

As an evaluation scale, we consider a linguistic term set with a unique granularity (seven), defined in the interval $[0,1]$ and denoted as $S$. Its semantics are as follows:

\begin{tabular}{|c|r|}
\hline Linguistic term & \multicolumn{1}{|c|}{ Semantics } \\
\hline$s_{0}=$ None $(N)$ & $(0,0,0.16)$ \\
\hline$s_{1}=$ Very Low $(\mathrm{VL})$ & $(0,0.16,0.33)$ \\
\hline$s_{2}=$ Low $(\mathrm{L})$ & $(0.16,0.33,0.5)$ \\
\hline$s_{3}=$ Medium $(\mathrm{M})$ & $(0.33,0.5,0.66)$ \\
\hline$s_{4}=\operatorname{High}(\mathrm{H})$ & $(0.5,0.66,0.83)$ \\
\hline$s_{5}=\operatorname{VeryHigh}(\mathrm{VH})$ & $(0.66,0.83,1)$ \\
\hline$s_{6}=$ Perfect $(P)$ & $(0.83,1,1)$ \\
\hline
\end{tabular}

\subsection{Aggregation of the experts' opinions}

As this step and the remaining steps are based on simple but thorough calculation, the proposed algorithm was coded in JAVA and run on $4 \mathrm{Ghz}$ Pentium Core 2 PC with windows XP. Reliable results are obtained in few seconds.

We suppose that there is no difference between all the experts' opinions. Therefore, through the application of equation 12 and 13, the aggregated acquired and required competence resources levels are shown in Table 3. 


\begin{tabular}{|c|c|c|c|c|c|c|c|c|}
\hline & & $w_{k j}(\%)$ & $C r_{k j}$ & C1 & $\mathbf{C 2}$ & C3 & C4 & C5 \\
\hline \multirow{8}{*}{ 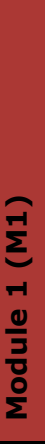 } & k) & .27 & $(\mathrm{H}, 0.33)$ & $(H, 0)$ & $(M, 0.33)$ & $(M,-0.33)$ & $(\mathrm{H}, 0.33)$ & $(H, 0)$ \\
\hline & (KE) & 22 & $(H,-0.33)$ & $(\mathrm{H},-0.33)$ & $(M, 0.33)$ & $(\mathrm{H},-0.33)$ & $(\mathrm{H},-0.33)$ & $(M, 0)$ \\
\hline & $(\mathrm{KP})$ & 13.27 & $(\mathrm{H}, 0.33)$ & $(\mathrm{H}, 0.33)$ & $L, 0.33)$ & $(M,-0.33)$ & $(\mathrm{H}, 0.33)$ & $(\mathrm{H},-0.33)$ \\
\hline & (PK-H) & 13.27 & $(\mathrm{H}, 0.33)$ & $(\mathrm{H}, 0.33)$ & $(M, 0)$ & $(L, 0.33)$ & $(\mathrm{H}, 0)$ & $(M, 0.33)$ \\
\hline & (EK-H) & 14.29 & $(\mathrm{VH},-0.33)$ & $(\mathrm{H},-0.33)$ & $(M,-0.33)$ & $(L, 0.33)$ & $(H, 0.33)$ & $(M, 0.33)$ \\
\hline & $(\mathrm{R})$ & 13.27 & $(\mathrm{H}, 0.33)$ & $(M, 0.33)$ & $(\mathrm{H}, \mathrm{O})$ & $(M,-0.33)$ & $(\mathrm{VH},-0.33)$ & $(\mathrm{H},-0.33)$ \\
\hline & (CC) & 12.24 & $(H, 0)$ & $(M, 0)$ & $(H, 0.33)$ & $(M, 0.33)$ & $(M, 0.33)$ & $(M, 0.33)$ \\
\hline & (B) & 9.18 & $(M, 0)$ & $(\mathrm{H}, 0.33)$ & $(\mathrm{H},-0.33)$ & $(L, 0.33)$ & $(\mathrm{H},-0.33)$ & $(\mathrm{H},-0.33)$ \\
\hline \multirow{8}{*}{$\begin{array}{l}\text { N } \\
\Sigma \\
\text { N } \\
0 \\
\frac{\partial}{3} \\
\frac{0}{\Sigma}\end{array}$} & $(\mathrm{T}$ & 13.79 & $(\mathrm{H}, 0)$ & $(M, 0)$ & $(M, 0$. & $(M, 0)$ & $(M, 0)$ & $(H, 0.33)$ \\
\hline & (KE) & 13.79 & $(\mathrm{H}, \mathrm{O})$ & $(M,-0.33)$ & $(H,-0.33)$ & $(\mathrm{H}, 0)$ & $(\mathrm{H}, 0.33)$ & $(M, 0.33)$ \\
\hline & $(\mathrm{KP})$ & 11.49 & $(M, 0.33)$ & $(\mathrm{H},-0.33)$ & $(M,-0.33)$ & $(M,-0)$ & $(\mathrm{H}, 0)$ & $(H, 0)$ \\
\hline & (PK-H & 13.79 & $(\mathrm{H}, 0)$ & $(\mathrm{VL}, 0.33)$ & $(L, 0.33)$ & $(M, 0.33)$ & $(M, 0)$ & $(M, 0)$ \\
\hline & (EK-H) & 12.64 & $(\mathrm{H},-0.33)$ & $(M, 0)$ & $(M,-0.33)$ & $(M, 0)$ & $(M,-0.33)$ & $(M, 0.33)$ \\
\hline & (R) & 12.64 & $(\mathrm{H},-0.33)$ & $(M, 0.33)$ & $(\mathrm{H}, 0)$ & $(M,-0.33)$ & $(\mathrm{H}, 0.33)$ & $(\mathrm{H},-0.33)$ \\
\hline & (CC) & 12.64 & $(H,-0.33)$ & $(M, 0)$ & $(\mathrm{H}, 0.33)$ & $(M, 0.33)$ & $(M, 0$ & $(M, 0.33)$ \\
\hline & (B) & 9.2 & $(M,-0.33)$ & $(\mathrm{H}, 0)$ & $(\mathrm{H},-0.33)$ & $(L, 0.33)$ & $(M, 0.33)$ & $(M, 0)$ \\
\hline \multirow{7}{*}{$\begin{array}{l}\sum_{m}^{m} \\
\frac{m}{3} \\
\frac{0}{5} \\
\frac{0}{\Sigma}\end{array}$} & (Tr & 15.58 & $(\mathrm{H}, 0)$ & $(M, 0)$ & $(\mathrm{H}, 0.33)$ & $(M, 0)$ & $(M, 0.33)$ & $(\mathrm{H}, 0)$ \\
\hline & (KP) & 14.29 & $(\mathrm{H},-0.33)$ & $(L, 0.33)$ & $(M,-0.33)$ & $(M, 0)$ & $(M, 0.33)$ & $(M,-0.33)$ \\
\hline & (PK-H) & 16.88 & $(\mathrm{H}, 0.33)$ & $(L, 0)$ & $(L,-0.33)$ & $(M,-0.33)$ & $(M, 0.33)$ & $(L, 0.33)$ \\
\hline & (EK-H) & 9 & $(\mathrm{H},-0.33)$ & $(M, 0$. & $(H,-0.33)$ & $\left(\mathrm{H}_{,}-\right.$ & $(\mathrm{H},-0.33)$ & $(M, 0.33)$ \\
\hline & (R) & 15.58 & $(\mathrm{H}, 0)$ & $(M, 0.33)$ & $(\mathrm{H}, 0.33)$ & $(M,-0.33)$ & $(H, 0)$ & $(\mathrm{H},-0.33)$ \\
\hline & $(\mathrm{CC})$ & 12.99 & $(M, 0.33)$ & $(M, 0.33)$ & $(\mathrm{H}, 0.33)$ & $(\mathrm{H},-0.33)$ & $(M, 0.33)$ & $(M, 0.33)$ \\
\hline & (B) & 10.39 & $(M,-0.33)$ & $(M, 0.33)$ & $(\mathrm{H}, 0)$ & $(M,-0.33)$ & $(M, 0.33)$ & $(\mathrm{H},-0.33)$ \\
\hline \multirow{7}{*}{$\begin{array}{l}\frac{\partial}{\Sigma} \\
\frac{0}{2} \\
\frac{0}{3} \\
\frac{0}{2}\end{array}$} & (TK) & 13.25 & $\left(H_{1}-0.33\right)$ & $(\mathrm{H}, 0.33)$ & $\left(\mathrm{VH}_{1}-0.33\right)$ & $(L, 0.33)$ & $(L, 0.33)$ & $(H, 0)$ \\
\hline & $(\mathrm{KP})$ & 18.07 & $(\mathrm{VH}, 0)$ & $(\mathrm{VH},-0.33)$ & $(\mathrm{VH}, 0)$ & $(L,-0.33)$ & $(L,-0.33)$ & $(\mathrm{H}, 0.33)$ \\
\hline & (PK. & 15.66 & $(\mathrm{H}, 0.33)$ & $(H, 0)$ & $(M, 0)$ & $(M, 0.33)$ & $(\mathrm{VH}, 0)$ & $(H, 0)$ \\
\hline & (EK-H) & 14.46 & $(\mathrm{H}, \mathrm{O})$ & $(\mathrm{H}, 0.33)$ & $(\mathrm{VH},-0.33)$ & $(\mathrm{VL}, 0.33)$ & $(L, 0.33)$ & $(H, 0)$ \\
\hline & (R) & 15.66 & $(\mathrm{H}, 0.33)$ & $(H,-0.33)$ & $(\mathrm{H}, \mathrm{O})$ & $(M,-0.33)$ & $(\mathrm{VH},-0.33)$ & $(\mathrm{H},-0.33)$ \\
\hline & $(\mathrm{CC})$ & 12.05 & $(M, 0.33)$ & $(M, 0)$ & $(H, 0.33)$ & $(H,-0.33)$ & $(\mathrm{H},-0.33)$ & $(M, 0.33)$ \\
\hline & (B) & 10.84 & $(M, 0)$ & $(\mathrm{H},-0.33)$ & .33) & $(M,-0.33)$ & $0.33)$ & 33 \\
\hline
\end{tabular}

Table 3. The aggregated acquired and required competence resources levels and their corresponding degree of importance

\subsection{Importance degree of required competence resources}

By equation 14, we can deduce the importance level of each required competence resource by each module $w_{k j}$ (Table 3 ) of our real problem.

\subsection{The TOPSIS based calculation process}

According to Table 3 and equations 15, 16, 17 and 18, the 2-tuple positive and negative ideal solution can be determined as follows (Table 4). 


\begin{tabular}{|c|c|c|c|}
\hline & $X_{j}^{+}$ & $\overline{X_{j}^{-}}$ \\
\hline \multirow{8}{*}{ 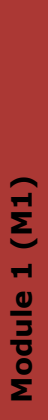 } & (TK) & $(\mathrm{H}, 0.33)$ & $(M,-0.33)$ \\
\hline & (KE) & $(\mathrm{H},-0.33)$ & $(M, 0)$ \\
\hline & (KP) & $(H, 0.33)$ & $(L, 0.33)$ \\
\hline & (PK-H) & $(\mathrm{H}, 0.33)$ & $(L, 0.33)$ \\
\hline & (EK-H) & $(\mathrm{VH},-0.33)$ & $(L, 0.33)$ \\
\hline & (R) & $(\mathrm{VH},-0.33)$ & $(M,-0.33)$ \\
\hline & (CC) & $(\mathrm{H}, 0.33)$ & $(M, 0)$ \\
\hline & (B) & $(\mathrm{H}, 0.33)$ & $(L, 0.33)$ \\
\hline \multirow{8}{*}{$\begin{array}{l}\text { N } \\
\Sigma \\
\text { N } \\
0 \\
\frac{1}{3} \\
\frac{0}{\Sigma}\end{array}$} & (TK) & $(\mathrm{H}, 0.33)$ & $(M, 0)$ \\
\hline & (KE) & $(\mathrm{H}, 0.33)$ & $(M,-0.33)$ \\
\hline & (KP) & $(\mathrm{H}, 0)$ & $(M,-0.33)$ \\
\hline & (PK-H) & $(H, 0)$ & $(\mathrm{VL}, 0.33)$ \\
\hline & (EK-I & $(\mathrm{H},-0.33)$ & $(M,-0.33)$ \\
\hline & (R) & $(\mathrm{H}, 0.33)$ & $(M,-0.33)$ \\
\hline & (CC & $(\mathrm{H}, 0.33)$ & $(M, 0)$ \\
\hline & (B) & $(\mathrm{H}, 0)$ & $(L, 0.33)$ \\
\hline \multirow{7}{*}{ 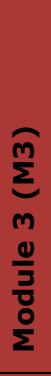 } & (TK) & $(\mathrm{H}, 0.33)$ & $(M, 0)$ \\
\hline & $(\mathrm{KP})$ & $(H,-0.33)$ & $(L, 0.33)$ \\
\hline & (PK-H) & $(\mathrm{H}, 0.33)$ & $(L,-0.33)$ \\
\hline & (EK-H) & $(\mathrm{H},-0.33)$ & $(M, 0.33)$ \\
\hline & (R) & $(\mathrm{H}, 0.33)$ & $(M,-0.33)$ \\
\hline & (CC) & $(\mathrm{H}, 0.33)$ & $(M, 0.33)$ \\
\hline & (B) & $(\mathrm{H}, 0)$ & $(M,-0.33)$ \\
\hline \multirow{7}{*}{ 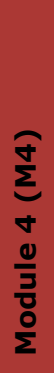 } & (TK) & $(\mathrm{VH},-0.33)$ & $(L, 0.33)$ \\
\hline & $(\mathrm{KP})$ & $(\mathrm{VH}, 0)$ & $(L,-0.33)$ \\
\hline & (PK & $(\mathrm{VH}, 0)$ & $(M, 0)$ \\
\hline & $($ EK-H) & $(\mathrm{VH},-0.33)$ & $(\mathrm{VL}, 0.33)$ \\
\hline & (R) & $(\mathrm{VH},-0.33)$ & $(M,-0.33)$ \\
\hline & (CC) & $(\mathrm{H}, 0.33)$ & $(M, 0)$ \\
\hline & (B) & $(\mathrm{H},-0.33)$ & $(M,-0.33)$ \\
\hline
\end{tabular}

Table 4. The 2-tuple positive and negative ideal solution ( $X_{j}^{+}$and $X_{j}^{-}$)

\begin{tabular}{|l|c|c|c|c|c|c|}
\cline { 2 - 7 } \multicolumn{2}{c|}{} & C1 & C2 & C3 & C4 & C5 \\
\hline \multirow{2}{*}{ Module 1 (M1) } & $d_{i j}^{+}$ & 0.78 & 1.26 & 1.75 & 0.44 & 0.9 \\
\cline { 2 - 7 } & $d_{i j}^{-}$ & 1.42 & 0.87 & 0.28 & 1.61 & 1.03 \\
\hline \multirow{2}{*}{ Module 2 (M2) } & $d_{i j}^{+}$ & 1.42 & 0.97 & 1.11 & 0.82 & 0.75 \\
\cline { 2 - 7 } & $d_{i j}^{-}$ & 0.66 & 0.95 & 0.92 & 1.19 & 1.06 \\
\hline \multirow{2}{*}{ Module 3 (M3) } & $d_{i j}^{+}$ & 1.34 & 1.16 & 1.22 & 0.73 & 1.03 \\
\cline { 2 - 7 } & $d_{i j}^{-}$ & 0.37 & 1.03 & 0.51 & 0.98 & 0.71 \\
\hline \multirow{2}{*}{ Module 4 (M4) } & $d_{i j}^{+}$ & 0.76 & 0.84 & 2.36 & 1.89 & 0.8 \\
\cline { 2 - 7 } & $d_{i j}^{-}$ & 1.97 & 2.21 & 0.27 & 1.25 & 1.77 \\
\hline
\end{tabular}

Table 5. The weighted Euclidian distance from $X_{j}^{+}$and $X_{j}^{-}$ 
Using equation 19 and 20, the 2-tuple linguistic weighted Euclidian distances are given in Table 5.

\subsection{Final selection results}

By reference to equation 21 , the candidate ranking is determined for each module according to its competence resources requirements (Table 6 ) in a descending order of $C C_{i j}$.

\begin{tabular}{|c|c|c|c|c|c|c|}
\hline$C C_{i j}$ & $C 1$ & $C 2$ & $C 3$ & $C 4$ & $C 5$ & Final ranking \\
\hline Module 1 (M1) & 0.65 & 0.41 & 0.14 & 0.79 & 0.53 & $C 4>C 1>C 5>C 2>C 3$ \\
\hline Module 2 (M2) & 0.32 & 0.5 & 0.45 & 0.59 & 0.59 & $C 4>C 5>C 2>C 3>C 1$ \\
\hline Module 3 (M3) & 0.21 & 0.47 & 0.3 & 0.57 & 0.41 & $C 4>C 2>C 5>C 3>C 1$ \\
\hline Module 4 (M4) & 0.72 & 0.72 & 0.1 & 0.4 & 0.69 & $C 2>C 1>C 5>C 4>C 3$ \\
\hline
\end{tabular}

Table 6. Candidate's ranking solution

\subsection{Results analysis}

At first glance to table 6 , it is clear that candidate $C 4$ is the best in the three modules M1, M2 and M3. Such results make a slight difference from the actual considered selection for each module. Indeed, candidate C4 does not teach any of these Modules.

Right now, we present an analysis of the resulting ranking order based on the results of table 3. In module (M1), C4 takes a big lead with a closeness coefficient of 0,79 since he has been attributed the best levels in the most important competence resources, namely, (EK-H), (KP), (TK) as it is shown in table 3. Compared to the next ranked candidate $\mathrm{C} 1, \mathrm{C} 4$ prevails through better levels in almost all the competence resources of the category Know-whom. In module (M2), we can smoothly notice a competition between the candidates, i.e., C4 and C5 are tied and the other candidates have close closeness coefficients. This is explained on the one hand by nearly identical importance degrees of the different competence resources required by this module and on the other hand by very close aggregated acquired levels. Again, C4 has a closeness coefficient higher than the others in module (M3). He has the best acquired levels in the most important competence resources; especially (KP) and (PK-H). Such levels have enabled him to overcome $\mathrm{C} 2$ that is characterized by higher aggregated levels in the remaining competence resources. In module 4 (M4), three candidates, C2, C1, and C5 are in competition. C4 is ranked the fourth and C3 is the fifth. C2 and C1 are both the best since they have the same closeness coefficient. Nevertheless, if we concentrate on the results of table 3, C2 predominates $\mathrm{C} 1$ especially in the most important competence resources [(TK), (PK), (EK-H), $(R)$ and $(C C)$ ]. Furthermore, in these competence resources, except (R), C2 obtained an aggregated acquired level higher than the required one. So, his resulting aggregated levels are considered as the reference. 
At the end, we can confirm the ability of the resulting ranking order to assist the actual department head, to make the right decision about different internal policies such as identifying individual substitution alternatives, improving the candidate's matching to modules based on a detailed comparison with regard to the reference competence resources levels, etc.

\section{Conclusion}

In this paper, a multi-criteria decision making method is presented in order to solve competence based evaluation and selection problem in a university context. The aim is to produce fair selection decisions that ensure the minimization of the gap between lecturers' competences and the corresponding module requirement levels. In this contribution, a 2-tuple linguistic representation model is well adapted to aggregate linguistic assessments of acquired and required competence resources generated by a group of appraisers. The resulting aggregated objective evaluations are therefore used as inputs of the TOPSIS method. The final ranking order provided according to the closeness coefficient helps the department head to the best management of the available candidates. It is a preliminary idea about the most suitable candidate to each module. It allows facing the circumstances of absenteeism, identifying the need of training, and so on. Nevertheless, the resulting ranking may be not enough to make the final decision about the best candidate to select. Several indecisive situations may occur and induce the impossibility to perform the right selection, namely, when one candidate is ranked as the best in several modules, when two candidates are tied. In such cases, it is opportune to exploit the ranking to solve an assignment problem with the consideration of several recurrent constraints such as candidate availability, candidate preferences ... Such issue constitute the object of our further work of research.

\section{References}

Banks, C.G., \& Roberson, L. (1985). Performance appraisers as test developers. Academic Management Revue, 10, 128-142.

Baron, J.N., \& Kreps, D.M. (1999). Strategic Human Resources: Frameworks for general managers. New York: Wiley.

Beer, M. (1981). Performance Appraisal: Dilemmas and Possibilities. Organizational Dynamics, 9(2), 24-36. http://dx.doi.org/10.1016/0090-2616(81)90036-X

Belkadi, F., Bonjour, E., \& Dulmet, M. (2007). Competency characterization by means of work situation modeling. Computers in Industry, 58(2), 164178. http://dx.doi.org/10.1016/j.compind.2006.09.005

Bennour, M., \& Crestani, D. (2007). Using competencies in performance estimation: From the activity to the process. Computers in Industry, 58(2), 151-163. http://dx.doi.org/10.1016/j.compind.2006.09.009 
Boucher, X., Bonjour, E., \& Grabot, B. (2007). Formalization and use of competencies for industrial optimization: A survey. Computers in Industry, 58(2), 98-117. http://dx.doi.org/10.1016/j.compind.2006.09.004

Chang, J.R., Cheng, C.H., \& Chen, L.S. (2007). A fuzzy-based military officer performance appraisal system. Applied Soft Computing, 7, 936-945. http://dx.doi.org/10.1016/j.asoc.2006.03.003

Chen, C.T. (2000). Extensions of the TOPSIS for group decision-making under fuzzy environment. Fuzzy Sets and Systems, 114, 1-9. http://dx.doi.org/10.1016/S0165$\underline{0114(97) 00377-1}$

Chen, C.T., Lin, C.T., \& Huang, S.F. (2006). Fuzzy approach for supplier evaluation and selection in supply chain management. International Journal of Production Economics, 102, 289-301. http://dx.doi.org/10.1016/j.ijpe.2005.03.009

De Andrés, R., Garcia-Lapresta, J.L., \& Martinez, L. (2010). A multi-granular linguistic model for management decision-making in performance appraisal. Soft Computing, 14, 21-34. http://dx.doi.org/10.1007/s00500-008-0387-8

Denisi, A.S., Cafferty, T.P., \& Meglino, B.M. (1984). A Cognitive View of the Performance Appraisal Process: A Model and Research Propositions. Organizational Behavior and Human Performance, 33, 360-396. http://dx.doi.org/10.1016/0030-5073(84)90029-1

Fan, Z.P., Feng, B., Sun, Y.H., \& Ou, W. (2009). Evaluating knowledge management capability of organizations: a fuzzy linguistic method. Expert Systems with Applications, 36, 3346-3354. http://dx.doi.org/10.1016/j.eswa.2008.01.052

Golec, A., \& Kahya, E. (2007). A fuzzy model for competency-based employee evaluation and selection. Computers \& Industrial Engineering, 52, 143-161. http://dx.doi.org/10.1016/j.cie.2006.11.004

Halouani, N., Chabchoub, H., \& Martel, J.M. (2009). Promethee-MD-2T method for project selection. European Journal of Operational Research, 195, 841-849. http://dx.doi.org/10.1016/j.ejor.2007.11.016

Harzallah, M., \& Vernadat, F. (2002). IT-based competency modelling and management: from theory to practice, Entreprise Engineering and Operations. Computers in Industry, 48, 157179. http://dx.doi.org/10.1016/S0166-3615(02)00003-9

Herrera, E., \& Martinez, L. (2000). A 2-tuple fuzzy linguistic representation model for computing with words. IEEE Transactions on Fuzzy systems, 8, 746-752. http://dx.doi.org/10.1109/91.890332 
Herrera, F., \& Martinez, L. (2001). The 2-tuple linguistic computation model. Advantages of its linguistic description, accuracy and consistency. International Journal of Uncertain Fuzziness Knowledge-Based Systems, 9, 33-48. http://dx.doi.org/10.1142/S0218488501000971

Hwang, C.L., \& Yoon, K. (1981). Multiple Attribute Decision Making Methods and Applications. Berlin Heidelberg: Springer. http://dx.doi.org/10.1007/978-3-642-48318-9

Jahanshahloo, G.R., Hosseinzadeh Lotfi, F., \& Izadikhah, M. (2006). An algorithmic method to extend TOPSIS for decision-making problems with interval data. Applied Mathematics and Computation, 175, 1375-1384.http://dx.doi.org/10.1016/j.amc.2005.08.048

Lee, E.S., \& Li, R.L. (1988). Comparison of fuzzy numbers based on the probability measure of fuzzy events. Computers \& Mathematics with application, 15, 887-896. http://dx.doi.org/10.1016/0898-1221(88)90124-1

Liao, X., Li, Y., \& Lu, B. (2007). A model for selecting an ERP system based on linguistic information processing. Information Systems, 32, 1005-1017. http://dx.doi.org/10.1016/j.is.2006.10.005

Martinez, L. (2007). Sensory evaluation based on linguistic decision analysis. International Journal of Approximate Reasoning, 44, 148-164. http://dx.doi.org/10.1016/j.ijar.2006.07.006

Mkaouar Hachicha, R., Dafaoui, E-M., \& El Mhamedi, A. (2009) Competence evaluation approach based on 2-tuple linguistic representation model. Proceedings of the 16th International Conference on Industrial Engineering and Engineering Management-IE\&EM, Beijing (China), 21-23 Oct., 2009.

Mkaouar Hachicha, R., Dafaoui, E-M., \& El Mhamedi, A. (2010). A competence based evaluation and selection problem by fuzzy linguistic computing. Proceedings of the 3rd. International Symposium on Computational Intelligence and Design-ISCID, Hangzhou (China), 29-31 Oct., 2010. http://dx.doi.org/10.1109/ISCID.2010.135

Moon, C., Lee, J., \& Lim, S. (2010). A performance appraisal and promotion ranking system based on fuzzy logic: An implementation case in military organizations. Applied Soft Computing, 10, 512-519. http://dx.doi.org/10.1016/j.asoc.2009.08.035

Pfeffer, J. (1995). Producing sustainable competitive advantage through the effective management of people. Academy of Management Executive, 9(1), 55-72.

Sadi-Nezhad, S., \& Damghani, K.K. (2010). Application of a fuzzy TOPSIS method base on modified preference ratio and fuzzy distance measurement in assessment of traffic police 
centers performance. Applied Soft Computing, 10(4), 1028-1039. http://dx.doi.org/10.1016/j.asoc.2009.08.036

Sanchez, P.J., Martinez, L., Garcia-Martinez, C., Herrera, F., \& Herrera-Viedma, E. (2009). A fuzzy model to evaluate the suitability of installing an enterprise resource planning system. Information Sciences, 179(14), 2333-2341. http://dx.doi.org/10.1016/j.ins.2008.12.020

Tai, W.S., \& Chen, C.T. (2009). A new evaluation model for intellectual capital based on computing with linguistic variable. Expert Systems with Applications, 36, 3483-3488. http://dx.doi.org/10.1016/j.eswa.2008.02.017

Torfi, F., Farahani, R.Z., \& Rezapour, S. (2010). Fuzzy AHP to determine the relative weights of evaluation criteria and Fuzzy TOPSIS to rank the alternatives. Applied Soft Computing, 10, 520-528. http://dx.doi.org/10.1016/j.asoc.2009.08.021

Wi, H., Oh, S., Mun, J., \& Jung, M. (2009). A team formation model based on knowledge and collaboration. Expert Systems with Applications, 36, 9121-9134. http://dx.doi.org/10.1016/j.eswa.2008.12.031

Wu, H.Y., Tzeng, G.H., \& Chen, Y.H. (2009). A fuzzy MCDM approach for evaluating banking performance based on Balanced Scorecard. Expert Systems with Applications, 36, 1013510147. http://dx.doi.org/10.1016/j.eswa.2009.01.005

Yoon, K., \& Hwang, C. (1995). Multiattribute decision making: an introduction. London: Sage Publications.

Zadeh, L. (1975). The concept of a linguistic variable and its applications to approximate reasoning. Information Sciences, Part I, Part II and Part III, 199-249, 301- 357, 43-80.

Journal of Industrial Engineering and Management, 2012 (www.jiem.org)



El artículo está con Reconocimiento-NoComercial 3.0 de Creative Commons. Puede copiarlo, distribuirlo y comunicarlo públicamente siempre que cite a su autor y a Intangible Capital. No lo utilice para fines comerciales. La licencia completa se puede consultar en http://creativecommons.org/licenses/by-nc/3.0/es/ 